\title{
Editorial
}

\section{The Coronavirus Pandemic in the Age of Social Media: A Chronology and Impacts on Peoples of African Descent ${ }^{1}$}

\author{
Fulgentius Nelson Lugemwa ${ }^{2}$
}

\section{In the media environment we live in, the truth can be difficult to find}

All one needs to become a reporter these days is a smartphone. One or two clicks later, one can launch an application and, boom, a ton of information avalanches and becomes available for expedient distribution. Messages travel fast and wide covering the globe in a matter of seconds. People can make videos in their bedrooms and suddenly become "experts" at what they are saying. These newly formed leaders in their fields are perceived as professionals and they convincingly disperse pearls of wisdom, especially to members of the general public that often have no time or desire to dig deeper and check the facts. Within their audiences, some have broad disregard for traditional expertise, and/or believe that there are no facts or that facts are whatever they state. There are also citizens eager to consume and distribute new and misleading information unknowingly. With President Donald Trump in the White House, the United States does not have a source of clear, science-based messages about the current crisis. With conflicting messages, the truth can be difficult to find.

As the pandemic broke out and the coronavirus showed up unexpectedly around the world and in our communities, other sites have filled in the vacuum of science-based news about COVID-19. Some of those sites include the John Hopkins University Coronavirus Resource Center (https://coronavirus.jhu.edu/), the University of Washington's Institute for Health Metrics and Evaluation (IHME, https://covid19.healthdata.org/united-states-of-america), the Centers for Disease Control and Prevention (CDC, https://www.cdc.gov/), and, for the more human anatomy and physiology inclined, MedCram (https://www.medcram.com/).

\footnotetext{
${ }^{1}$ Submitted on April 28, 2020. Accepted on April 29, 2020. Last changes received on April 30, 2020.

${ }^{2}$ Penn State University. York, Pennsylvania, USA. Email: ful4@psu.edu .
} 
The severe acute respiratory syndrome coronavirus (SARS-CoV) is a type of coronavirus that infects bats, humans, and other mammals. SARS-CoV-2 is an enveloped positive sense single-stranded RNA virus that enters its host by binding to the angiotensin-converting enzyme 2 (ACE2) receptor. It belongs to the beta-coronavirus group of viruses. Two other wellknown strains of the virus have caused outbreaks of severe respiratory disease in humans, namely, severe acute respiratory syndrome coronavirus (SARS-CoV or SARS-CoV-1), which caused a severe outbreak eighteen years ago (2002-2004). This virus was known as simply (SARS). The severe acute respiratory syndrome caused by SARS-CoV was first identified in Foshan, Guangdong, China, in November 2002. Over 8,000 people from different countries were infected, and at least 700 died worldwide. The other coronavirus of recent note was the Middle East Respiratory Syndrome (MERS), which is a viral respiratory illness first reported in Saudi Arabia in 2012 and spread to other countries. Most people infected by MERS-CoV developed severe respiratory illness, including fever, cough, and shortness of breath. The current pandemic has been brought about by the severe acute respiratory syndrome coronavirus 2 (SARS-CoV-2), which causes coronavirus disease 2019 (COVID-19). The current COVID19 had killed about 140,00 people by the middle of April 2020. It started in Wuhan, Hubei province- China. There are hundreds of other strains of SARS$\mathrm{CoV}$, all of which are only known to infect non-human species. Bats are a major reservoir of many strains of SARS-related coronaviruses.

\section{COVID-19 as breeding ground to opportunists and abusers}

Pieces of advice on how to prevent being infected by the virus are plentiful. The proper way to wash hands with soap and the duration it takes to wash well were clearly demonstrated on many channels. After washing the hands, emphasis was put on not touching anyone's face, including your own. This was and still is a pretty standard hygienic practice that can prevent the spread of the flu virus and other easily transmissible diseases. Yet, juxtaposed with science-based information, mercenaries of home remedies offered other recommendations to ward off coronavirus, like eating garlic, onions, ginger, or lime. Some "experts" intimated that salt would kill the virus if taken in the right amount. Others said that taking a cold drink would force coronavirus into the lungs, and that the best way to avoid or fight severe acute respiratory syndrome coronavirus 2 (SARSCoV-2), the causative agent of Coronavirus Disease 2019 (COVID-19) was to ingest hot drinks, which would channel the virus to the stomach, where the $\mathrm{pH}$ is low and kill the virus. Lists of fruits and vegetables are routinely sent out via social media platforms, indicating those that should be avoided, especially the ones with a high $\mathrm{pH}$. Some fruits were listed as having a $\mathrm{pH}$ of greater than 20 ! 
At first, the message on the use of masks was not clear. Some health officials were not recommending wearing of masks by those people who had not yet been infected by the virus. They provided all sorts of reasons, including the one on hygiene, claiming that users will contaminate their faces when putting and removing masks. Despite those early warning, there were several videos demonstrating simple ways of making masks. As people were sending out all sorts of videos, the virus was spreading everywhere, including on cruise and military ships and on all continents, except Antarctica. The pandemic was taking a hold on Earth.

Dictators saw an opportunity to suppress the people they lead even more. In Uganda, any politician caught distributing food, or any form of assistance to the masses, would be charged with attempted murder. President Yoweri Museveni seems to not want opposing politicians to earn credit during the pandemic. In other countries, especially those under autocratic rule, lockdowns were swift and hard on the entire population. People are locked in house while the government is busy eating all the money borrowed from international bodies, like the World Bank, to fight coronavirus. After the lockdown in Uganda, a message circulated on Whatsapp. The introduction read: "Rich Ugandans in posh gated estates ever wondering why the average Ugandan isn't alarmed by coronavirus. They say Ugandans are stupid. They are not self-isolating, not washing their hands, not sanitizing. We aren't stupid bro. This is the life we live every day. No healthcare coverage. No promise of food/running water. State apathy. Welcome to the party. Grab a seat. Pull out the popcorn and settle in. It's hard to be alarmed when your entire existence is an alarm."

\section{A chronology of COVID-19}

As far as I know, the coronavirus was first reported widely in Wuhan, China, on December 31, 2019. It quickly spread across the world and by April 30, 2020 (circa 13:00 in Pennsylvania) it had infected over 3.2 million people worldwide of which nearly 230,000 have died (https://www.worldometers.info/coronavirus/). In early January 2020, Chinese scientists sequenced the entire genome for SARS-CoV-2 and published it online. Researchers at the Wuhan Institute of Virology in China compared its genome to a digital library of known viruses and found a $96 \%$ match with coronavirus samples taken from horseshoe bats from Yunnan. Additionally, this novel coronavirus (2019-nCoV) that has infected millions of people around the globe since December 2019, the SARS-COV or SARS-COV-1, and the bat SL-CoVC45 have similar genetic makeup (Wu et al. 2020 Nature 579:265-269). This novel coronavirus multiplies and spreads fast and is very contagious. By March 2020, there were more than 1,800 journal articles published about the virus and COVID19 and nearly 200,000 hits in Google Scholar. Common symptoms include fever, dry cough, and tiredness. Some people also experience aches and pains, nasal congestion, runny nose, sore throat, anosmia, and diarrhea. 
The Centers for Disease Control and Prevention presented the following list of conditions that might explain why many people are dying because of complications brought about by COVID-19.

COVID-19 is a new disease and there is limited information regarding risk factors for severe disease. Based on currently available information and clinical expertise, older adults and people of any age who have serious underlying medical conditions might be at higher risk for severe illness from COVID-19. Based upon available information to date, those at high-risk for severe illness from COVID-19 include:

People 65 years and older, people who live in a nursing home or long-term care facility. People of all ages with underlying medical conditions, particularly if not well controlled, including

- People with chronic lung disease or moderate to severe asthma

- People who have serious heart conditions

- People who are immunocompromised

- Many conditions can cause a person to be immunocompromised, including cancer treatment, smoking, bone marrow or organ transplantation, immune deficiencies, poorly controlled HIV or AIDS, and prolonged use of corticosteroids and other immune weakening medications.

- People with severe obesity (body mass index [BMI] of 40 or higher)

- People with diabetes

- People with chronic kidney disease undergoing dialysis

- People with liver disease

Oblivious to the extent of the problem and the dangers of not coming out with a clear, science-based message, on April 14, 2020, President Trump vowed to cut off funding to the World Health Organization. The response from WHO was swift. "COVID-19 does not discriminate between rich nations and poor, large nations and small. It does not discriminate between nationalities, ethnicities or ideologies," Tedros Adhanom, the Director General of the World Health Organization said, "Neither do we. This is a time for all of us to be united in our common struggle against a common threat - a dangerous enemy."

China has accused the United States of having manufactured the virus and the United States has accused the Chinese of having engineered the virus in a laboratory that is located close to where the first patient was staying. China alleges that the Americans conducted a military exercise near the wet market, where supposedly the outbreak started and introduced the virus there. The use of $5 \mathrm{G}$ technology has been blamed for making the body weak and prone to the virus. It was alleged that the virus was killing people in areas that had a huge deployment of $5 \mathrm{G}$ towers. 
The coronavirus moved from Wuhan, Hubei province through Iran, then Europe, North America, and then, the southern continents, such as Africa and South America, wrecking lives, killing people, and decimating economies. In Italy, the number of innocent people dying everyday was unheard of in modern times. Italy was the first nation in the Western World to order a lockdown with the vigorous use of the military in an effort to control the spread of coronavirus. Stimulus packages were quickly passed by different governments and communities to try and turn things around, as the number of people filing for unemployment benefits rose exponentially in several developed countries.

On January 19, 2020, a 35-year-old man presented to an urgent care clinic in Snohomish County, Washington. That was first widely reported case in the United States. Soon, panic engulfed the entire nation, as more cases in a nursing home in the same state began to emerge. The fear of shortages and the panic resulted in buying and hoarding toilet paper as the first item on the shopping list, followed by sanitizer, and other cleaning products, including Lysol, and more recently, meat products. In a few days following the first case in the USA, people began buying and hoarding stuff they have never possessed before. Canned and dried foods were exceedingly popular. Workers in several grocery store chains could not keep up with the demand and often, shelves were found empty by the panicked shoppers. The demand for and sales of the movie Contagion, that follows the rapid progress of a lethal airborne virus that kills within days, went up after the first case in Washington was reported.

\section{COVID-19 reaches New York City, USA}

In early March 2020, news communicated that COVID-19 had reached one of the most densely populated megacities in the world, New York City. In the first few days, the rate of infection in the New York City area mirrored what had been happening in Italy. The number of new cases and deaths were rising rapidly and, to make matters worse, there was an acute shortage of medical personnel and supplies, including personal protective equipment (PPE), masks, cotton swabs, ventilators, and body bags. Old warehouses were hurriedly converted to makeshift morgues. People with underlying respiratory and/or cardiovascular conditions were dying in large numbers. Treatment with oxygen, by means of ventilators, seemed to be the best available solution. In most cases it did not work. Images of crying doctors were common on TV screens. They showed exhausted nurses and doctors who were trying to save lives but were outnumbered by the sick and outplayed by the virus. In the end, too many patients were dying, leading to frustration and pain. One emergency room doctor who had also contracted the virus and recovered, could not take it anymore. She committed suicide. Thousands of medical students were being fast-tracked into the field to help 
fight SARS-CoV-2. Retired doctors were being called out of retirement and given a crash course in caring for COVID-19 patients. The rush to save lives had its consequences on those on the frontline. Unprotected, prolonged patient contact, as well as certain exposures, including some aerosolgenerating procedures, were associated with SARS-CoV-2 infection among health care personnel, leading to death.

On March 27, 2020, President Donald Trump invoked the Defense Production Act, directing General Motors to produce ventilators needed for the coronavirus outbreak, following weeks of increasingly loud pleas from state governors and city mayors to put that powerful statute into use. It was reported that after the several reported cases in Washington state, facilities in New York, for example, knew that the frail and aging citizens were especially vulnerable to the virus. But because of limited access to testing, lack of ventilators, and protective equipment, the scourge could not be stopped. Nursing homes in Brooklyn, NY and other places became death traps. By April 11, 2020, the United States had suffered the largest number of coronavirus deaths in the world. The country's toll had climbed to more than 20,000 and as many as 2,000 people were dying every day.

Meanwhile, in the southern USA metropolis of New Orleans, numbers of coronavirus cases were rapidly rising during the time New York City was fighting to save lives. Quickly, the outbreak in New Orleans become one of the most explosive in the country. "I think it all boils down to Mardi Gras," said Dr. F. Brobson Lutz Jr., a former health director of New Orleans and a specialist in infectious diseases. "The greatest free party in the world was a perfect incubator at the perfect time." And after that big party, the Big Easy, name often given to New Orleans, had to pay a big price just like the City of Brotherly Love, Philadelphia, paid during the 1918-1919 influenza pandemic for allowing similar mass gatherings.

In many ways, the coronavirus was non-discriminatory. It infected the rich and the poor in a similar way. Celebrities, movie and sports stars, common citizens, and politicians were testing positive at an alarming rate. On March 13, 2020, Sophie Grégoire Trudeau, wife of Canadian Prime Minister Justin Trudeau, tested positive for coronavirus after returning from a trip to London. On March 16, 2020 at 2:18 p.m. British actor and musician, Idris Elba, shared his diagnosis via Twitter: "This morning I tested positive for Covid 19. I feel ok, I have no symptoms so far but have been isolated since I found out about my possible exposure to the virus. Stay home people and be pragmatic. I will keep you updated on how I'm doing. No panic." His post received 1.35 million likes. The UK Prime Minister, Boris Johnson, ended up in the intensive care unit (ICU) after testing positive for coronavirus. The Royals were not spared either. On March 25, 2020, Prince Charles tested positive. Chris Cuomo, the brother of the 
Governor of New York and CNN reporter also tested positive for coronavirus and later his wife tested positive too.

The highly contagious SARS-CoV-2 seemed to be a virus that could not be stopped and could infect anybody. But that was not true; the virus is not a great equalizer. The rich had the opportunity to ride it out. They are also privileged to more space, while the poor use public transport and have no good access to healthcare. In the United States, African Americans and Hispanics have been hit harder medically and financially by COVID-19 than Caucasians.

\section{Impacts on our daily routines}

Universities closed and faculty members were asked to deliver classes remotely. Not every professor is tech-savvy and many struggled, but thanks to the dedication and hard work of faculty and IT professionals, teaching catastrophes were avoided in many institutions of higher learning. Government and private company employees began operating from home, as lockdowns were mandated from one state to another. Working from home and using platforms like Zoom, Skype, Google Meet (formerly Google Hangouts), Piazza, GoToWebinar, TeamViewer, Kaltura, and many others became the new norm. Creativity was immediately demanded. There was a meteoric increase in smart tele-medicine as patients sought different types of treatment from their homes. Stock prices of Zoom and Netflix went through the roof, even as the overall market was tanking. More people were staying and working from home. In just a week, the stock market had lost almost all the gains it had accumulated during the last decade. Those staying at home and the many virus-wary across the Northern Hemisphere from Trump to schoolchildren, thought that the pandemic would fade in hot weather as some viral diseases do, even as data from other hot places proved otherwise. Let us remember, where the Northern Hemisphere experiences warmer temperatures, the Southern Hemisphere experiences cooler temperatures, and vice-versa.

As the pandemic rages on, stay at home orders were issued in different cities, counties, states, and countries. It was determined that coronavirus disease 2019 (COVID-19) was most often spread from person to person among close contact (about 6 feet, circa 1.8 meters). Social distancing has become the best medicine, in addition to wearing masks and practicing cleaning practices, to decrease the incidence of COVID-19 (Figures 1-2). 

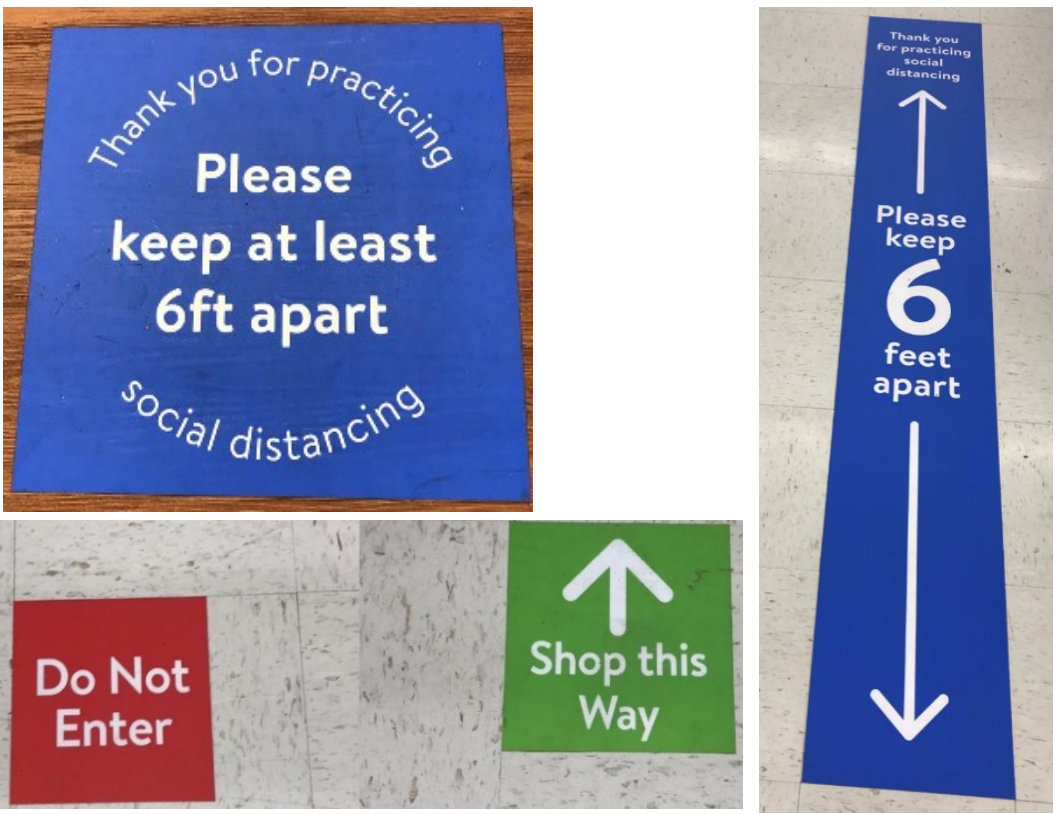

Figure 1. Common signs seen in local establishments directing customers to social distance themselves.

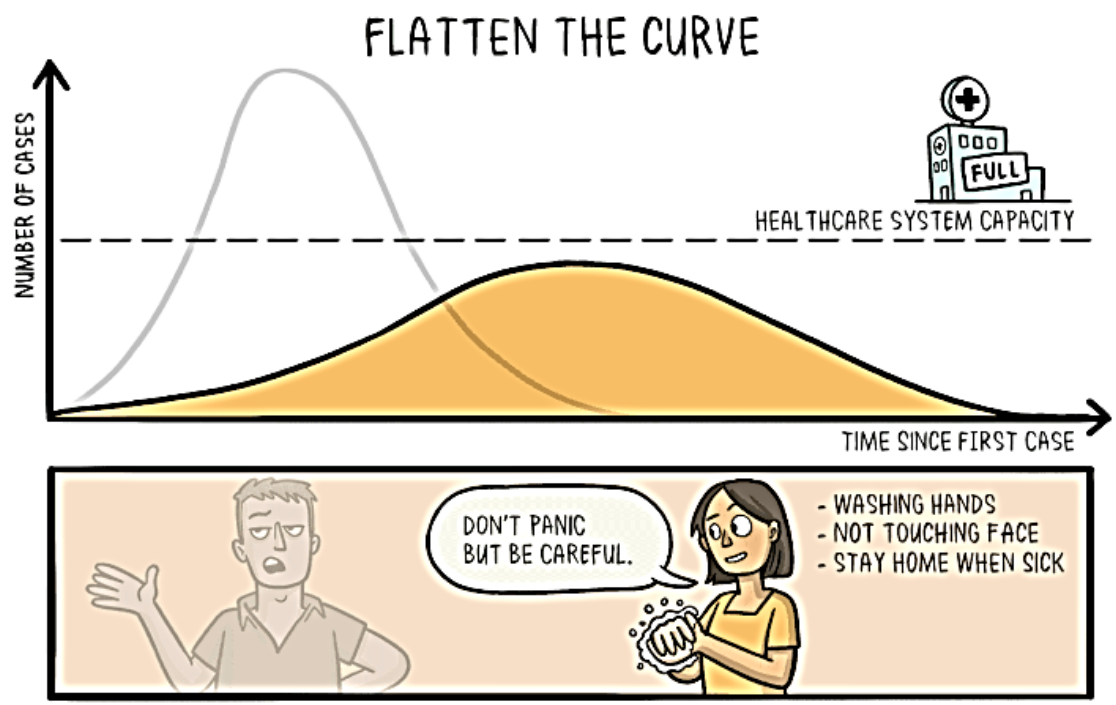

Figure 2. Social distancing to ease health care system capacity and protect our lives. https://commons.wikimedia.org/wiki/File:Covid-19-curves-graphic-social-v3.gif 
A major concern is the phenomenon of asymptomatic transmission. The possibility that people could pass along the disease even though they showed no symptoms, underscored the challenge of containing the pandemic. Governors and other state officials have demanded more testing to understand the magnitude of the spread, which could ultimately lead to containment. It is estimated that between $25-50 \%$ get the virus but do not get COVID-19 disease. Those seemingly healthy people could pass the virus to others who would end up getting sick.

\section{COVID-19 in Africa and its impact in people of African descent}

On March 11, 2020, the World Health Organization (WHO) declared the coronavirus outbreak a pandemic. The following day, members of the Natural Products Research Network for East and Central Africa (NAPRECA) got busy trying to find a drug that could deal with the pandemic. This organization has many hard-working researchers and scholars of natural products. One member proposed that he wanted to grow the virus in his laboratory even though he did not have a Level 3 laboratory that was certified to carry out such work. He insisted that he was ready to grow the virus in eggs and that he had the necessary experience. His plan was to find drugs that could kill the virus, and there were plenty of people who promised to send him crude extracts that they had been working on, using different biological assays. Other faculty members promised to do docking studies, since the proteins on the surface of the novel virus were now known and that studying protein-ligand interactions was the fastest way to decipher structures for the best drug candidates. A few veterans in the field of natural products warned that flavonoids, compounds which many laboratories are working on in East and Central Africa, had no history of being potential drugs but work well as antioxidants. There was a lot of excitement and desire to knock the virus dead. "Please don't grow the virus in your lab because if it escapes it's going to kill all of us," one prominent professor warned. The crack of his voice could be heard over the social media waves. Students in different African universities started looking for recipes to make sanitizer. The less sophisticated without any experience wanted to do the same and were asking whether the local moonshinetype distillates, which are only $34 \%-40 \%$ alcohol could be used. Others pointed out that Vodka was more potent.

The virus took a bit longer to get to Africa and before it reached the continent, it was not taken seriously. Some were convinced that the virus would not survive on the heat of the summer in the African continent and those Africans that had contracted the virus in other parts of the world were not dying. "Our African ancestors are fighting back and protecting the continent after all the injustices. This is a White man's disease," a student from Tanzania wrote. That was in reference to the way Africa has been treated by the West for a long time, including slavery and other unjust policies. When the Dominican Republic had a couple of hundred confirmed COVID-19 cases, Haiti had none. One observer wrote, "The 
two countries share the same island-Hispaniola but look at their numbers. It's clear that Haitian Voodism is working full time."

Sadly, during the current pandemic, there has also been xenophobia and religious persecution in some places. African foreign nationals in Guangzhou, China were reportedly evicted from their homes and denied services, in an attempt by the Chinese officials to blame them for a second wave of coronavirus cases. Guangzhou, also called "Little Africa," has the highest concentration of Africans residing in China, hailing mainly from Uganda, Nigeria, Ghana, and Kenya. One April 3, 2020, two French doctors were accused of racism after a TV debate in which one suggested carrying out vaccine trials in Africa to see if a tuberculosis vaccine would prove effective against coronavirus. With so few cases in Africa, most African leaders, and the people they lead argued that countries with much more large number of cases would be the best places for testing vaccines. In India, there was coronavirus conspiracy theories targeting Muslims, which forced their leaders to hide in mosques. Hindus used the hashtags like \#CoronaJihad, \#CrushTablighiSpitters, \#MuslimMeaningTerrorist, and \#BioJihad to spread misinformation. Further away from Africa, in the United States, African Americans were worried and did not want to wear masks, because those who wear masks are usually associated with committing crimes. They reasoned that if they started wearing masks, the police would have a field day arresting them.

More global impacts

The pandemic has cost lives and livelihoods and it has also shaken fundamental assumptions about American exceptionalism, the belief that the USA has played a singular role for decades after World War II as an example to the world. Also, the pandemic has exposed the USs erratic President who often does not follow scientific guidance and the absence of a sufficiently robust public health care system and social safety net. Right from the beginning, the messaging in the US was bad. People at a rally clapped when Trump told them that the virus was not going to get to the US. He also gave conflicting messages to those provided by Dr. Anthony Fauci, an expert on his Coronavirus Taskforce.

Sweden took a different path. They decided to take care of the elderly that are more likely to die if they contracted the virus, and the country did not order a lockdown. The government left the rest of its people to practice social and physical distancing, another way to try allowing a natural acquisition of herd immunity.

As coronavirus rages and destroys economies and kills people, some world leaders were praised for their leadership in containing the situation. New Zealand's Prime Minister, Jacinda Ardern, was praised for her pragmatism to fight the pandemic. Northern Island's prime minister, Leo Varadkar, was a general practitioner in Dublin before entering politics and worked as a doctor during the coronavirus pandemic. South Korea's, Moon Jea-in, won an election, partly 
because of the way he handled the coronavirus in his country. Before the outbreak, there had been calls for his impeachment.

\section{The Future}

The pandemic is not a hurricane or a wildfire. It is not comparable to Pearl Harbor or 9/11. Such disasters are confined in time and space. The SARS-Cov-2 virus will linger through the year and across the world. "Everyone wants to know when this will end," said Devi Sridhar, a public-health expert at the University of Edinburg. "That's not the right question. The right question is: How do we continue?"

With behavior change, new drugs, together with new diagnostics, antibody tests, patient- and contact-tracing technologies, disease surveillance and other early-warning tools, or a potent vaccine, the human race will survive, and will be better equipped to fight the current pandemic and also the anticipated next 'wave' or a new global pandemic. 